\title{
Neonatal outcomes of singleton live births with vanishing twin syndrome following double embryos transfer in assisted reproductive technology: a retrospective cohort study
}

Junfang Yan, Yichun Guan* ${ }^{*}$, Hongfang Fan, Mingkun Mu, Simin Sun, Wenjun Geng, Wei Zheng and Zhiying Xiao

\begin{abstract}
Background: Women with vanishing twin syndrome are associated with increased risks of adverse neonatal outcomes, such as preterm birth (PTB) and low birthweight (LBW), compared with those in singleton live births following single embryo transfer (SET) in assisted reproductive technology (ART).

Methods: Anonymized data on all cycles performed in China were obtained from the Reproductive Medicine Department at the Third Affiliated Hospital of Zhengzhou University, which had involved 127597 cycles following double embryos transfer (DET), including 54585 fresh embryos transfer (ET) cycles and 73012 frozen embryos transfer (FET) cycles. In addition, the obstetric outcomes, such as gestation age, PTB, small for gestation age (SGA), birthweight (BW), LBW, congenital malformation, pediatric admission and Neonatal Intensive Care Unit (NICU) admission in the fresh ET and FET cycles, were analyzed. Moreover, logistic regression analysis was performed to adjust the confounders, including age of women, body weight index (BMI), value of $\mathrm{AMH}$, infertile years, current cycle, antral follicles, cause of infertility, number of oocytes retrieved, endometrial thickness at the date of transplantation, number of high-quality embryos, and embryo stage.
\end{abstract}

Results: In the fresh ET cycles, the BW and gestational age in study group were lower than those in control group, which were (2962.4 \pm 563.1 vs. $3104.9 \pm 498.5, p=0.000$ ) and (262.8 \pm 8.4 vs. $268.9 \pm 13.9, p=0.000$ ), respectively. Relative to control group, the study group was linked with increased risks of PTB (adjusted odds ratio (aOR) 2.45, 95\% Cl:1.98-3.03, adjusted $p=0.000$ ), LBW (aOR2.11, 95\% Cl:1.67-2.65, adjusted $p=0.000$ ), pediatric admission (aOR 2.55, 95\% Cl2.07-3.13, adjusted $p=0.000$ ), and NICU admission (aOR 1.98, 95\% Cl1.32-2.96, adjusted $p=0.001$ ), but there were no statistically significant differences in the risks of SGA (aOR 1.09, 95\% Cl0.82-1.45, adjusted $p=0.960$ ) and congenital malformation (aOR 0.94, 95\% Cl0.53-1.68, adjusted $p=0.640$ ) between the two groups. In the FET cycles, the gestational age and BW in study group were lower than those in control group, which were $(263.0 \pm 15.7 v$ v. $273.0 \pm 10.5, p=0.000)$ and (3099 $\pm 662.1 \mathrm{vs} .3352 \pm 671.5)$, respectively. The study group was associated with increased risks of PTB (aOR2. 45, 95\% Cl: 2.23-3.43, adjusted $p=0.000$ ), LBW (aOR 2.67, 95\% Cl: 2.13-3.34, adjusted $p=0.000$ ), pediatric admission (aOR2.62,95\% Cl2.14-3.21, adjusted $p=0.000$ ), and NICU admission (aOR 2.22, 95\% Cl1.43, 3.46, adjusted $p=0.001$ ) compared with those in control group, but differences in the risks of SGA (aOR $0.98,95 \% \mathrm{Cl} 0.71-1.36$, adjusted $p=0.730$ ) and congenital malformation (aOR 0.99, $95 \% \mathrm{Cl} 0.60$, 1.63 , adjusted $p=0.940$ ) between the two groups were not statistically significant.

(Continued on next page)

\footnotetext{
*Correspondence: lisamayguan@163.com

The Third Affiliated Hospital of Zhengzhou University, Zhengzhou City, China
}

(c) The Author(s). 2019 Open Access This article is distributed under the terms of the Creative Commons Attribution 4.0 International License (http://creativecommons.org/licenses/by/4.0/), which permits unrestricted use, distribution, and reproduction in any medium, provided you give appropriate credit to the original author(s) and the source, provide a link to the Creative Commons license, and indicate if changes were made. The Creative Commons Public Domain Dedication waiver (http://creativecommons.org/publicdomain/zero/1.0/) applies to the data made available in this article, unless otherwise stated. 
(Continued from previous page)

Conclusions: Our study finds that singleton live births with VTS have higher risks of LBW, PTB, pediatric admission and NICU admission than those without VTS in both the fresh and frozen cycles, even after adjusting for confounders. However, no increased risks of SGA or congenital malformation are observed in singleton live births in both the fresh and frozen ART cycles following DET.

Keywords: Preterm birth, Low birthweight, Assisted reproductive technology, Single embryo transfer, Fresh embryos transfer cycles, Frozen embryos transfer cycles

\section{Background}

Assisted reproductive technology (ART) is under rapid development since the birth of the first infant through the in-vitro fertilization (IVF) technique. This marked the practice from sophisticated experimental techniques to conventional medical care. However, compared with spontaneous conceptions, ART has a low pregnancy rate, the insufficient embryos and culture techniques. Therefore, clinicians frequently transfer multiple embryos to maximize the chance of pregnancy [1, 2]. Meanwhile, ART has resulted in a dramatically increased incidence of multiple pregnancies over the past 4 decades [3]. Specifically, multiple pregnancies are indicative of an increased risk of preterm birth (PTB) and perinatal death, which are recognized as the adverse outcomes related to the interventions of ART [4, 5]. Some national policies and guidelines usually recommend selective single embryo transfer (SET) for women with favorable prognosis and those aged less than 35-38 years $[6,7]$. Typically, SET can markedly reduce the rate of multiple pregnancies following ART [8]. Nowadays, successful outcomes have been increasingly defined as the healthy monocyesis and singleton live births $[9,10]$. Yet, we are concerned about the outcomes of single pregnancy throughout the process of pregnancy. So, what is the difference between a single pregnancy with vanishing twin syndrome (VTS) and that without VTS? In 1945, Stoeckel had first proposed the spontaneous reduction of a fetus in a twin pregnancies, which was referred to as the phenomenon of "vanishing twins." Dickey et al. found that $50 \%$ patients who had 3 or more gestational sacs would have spontaneous reductions before the first 12 weeks of pregnancy, and these patients were linked with higher risks of PTB and LBW [11]. It is suggested in one study that, people with spontaneous reduction of the initial multiple pregnancies to a singleton pregnancy were associated with increased risks of adverse prenatal outcomes, such as PTB and LBW, compared with those of singleton live births with SET [12]. In addition, some other studies show that the risk of fetal growth restriction (FGR) with VTS in an early twin pregnancy is elevated relative to that in the initial single pregnancy, and the later occurrence of VTS was related to a higher risk [13]. Nonetheless, no existing study has specially delineated the adverse obstetric outcomes of twin pregnancy with VTS. Therefore, the current retrospective cohort study was carried out to compare the neonatal outcomes in singleton live births between groups with and without VTS following double embryos transfer (DET).

\section{Methods \\ Populations}

From January 1st, 2005 to October 1st, 2018, anonymized data on all cycles performed in China were obtained from the Reproductive Medicine Department at the Third Affiliated Hospital of Zhengzhou University, which had involved 127597 cycles following DET, including 54585 fresh ET cycles and 73012 FET cycles. Typically, the infertile couples with tubal factors or male factor (such as lean and weak sperm disease) were included in this study. Moreover, women with multiple births, uterine diseases, endocrine and medical diseases, ovarian diseases, and pre-implantation genetic diagnosis/ screening (PGD/S) were excluded from this study. Furthermore, cycles with donor oocytes, donor embryos, and incomplete records were also ruled out of this study. For our study, the ART cycles with DET that resulted in singleton live births would be analyzed for their obstetric outcomes, including gestation age, PTB, SGA, BW, LBW, congenital malformation, pediatric admission and NICU admission in both fresh ET and FET cycles. Additionally, the fetal heart rate at 7 weeks of gestation was monitored with three-dimensional (3D) ultrasound, and cycles with two fetal hearts and two gestational sacs were enrolled as the study group. In addition, cycles with single fetal heart and single gestational sac were included as the control group, from which 1576 and 2173 cases were extracted at a ratio of 10:1 using the system sampling method. (Details are presented in Figs. 1 and 2). Baseline characteristics of both cohorts in fresh ET and FET cycles are presented in Table 1, including maternal age (year), body mass index (BMI), infertile year, cause of infertility (tubal disease or male factor), current cycle, blood follicle-stimulating hormone $(\mathrm{bFSH}), \mathrm{bE} 2$, blood luteinizing hormone (bLH), prolactin (PRL), anti-mullerian hormone $(\mathrm{AMH})$, antral follicle count (AFC), number of oocytes retrieved, number of available embryos, number of 


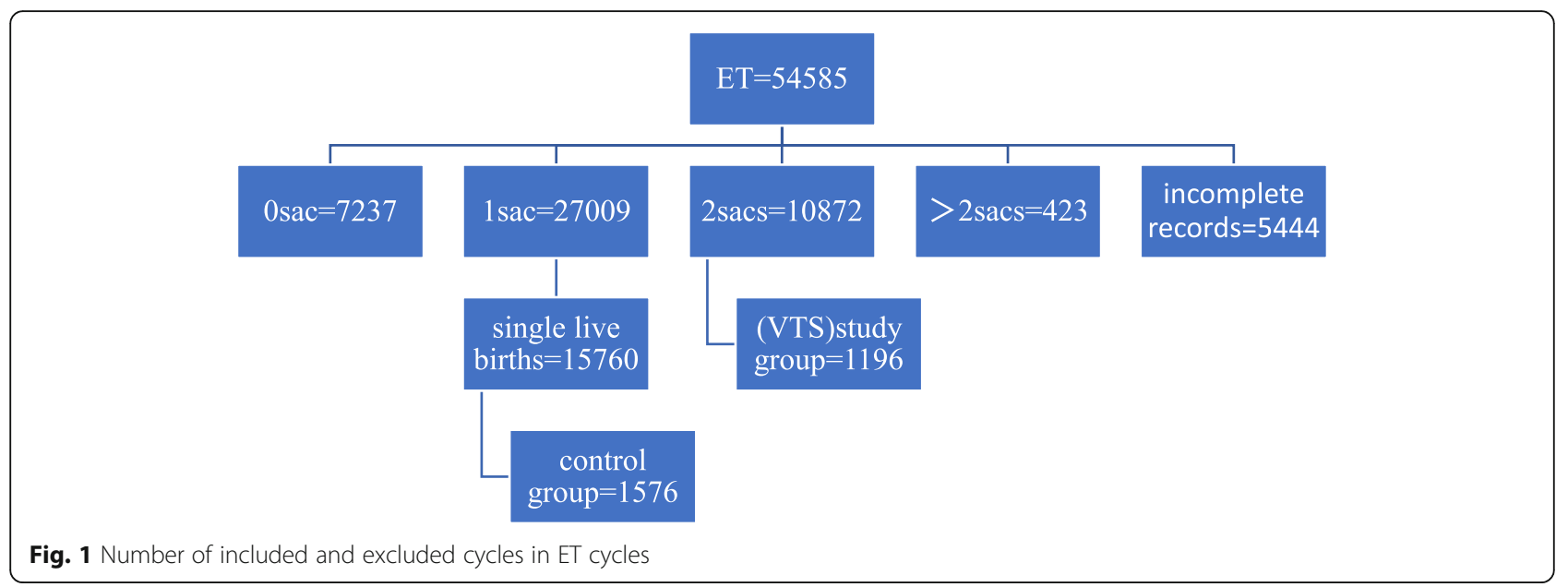

high quality embryos, stage of embryo transfer, endometrial thickness at the date of transplantation, and mode of delivery (cesarean section and vaginal delivery).

\section{Embryo transfer and follow-up}

2 fresh or frozen embryos would be transplanted into the uterus of each patient by doctors. Subsequently, from that day, the patient receives luteal support treatment,including progesterone injection and vaginal progesterone release gel, and gradually reduced after 45 days of transplantation. Beta human chorionic gonadotropin ( $\beta$-hCG) in blood was tested at 14 days after DET. Professionals at the hospital would obtain patient information by means of telephone interview and retrieval of the hospitalization system throughout the process from pregnancy to birth; afterwards, they would upload all materials into the Reproductive Center Database.

The primary endpoints of our study were obstetric outcomes, including PTB (gestational age of $<37$ weeks), small for gestation age (SGA), LBW (BW of $<2500 \mathrm{~g}$ ), congenital malformation (such as Trisomy 13/18/21, congenital heart disease (CHD), polydactyly/syndactyly and others), pediatric admission (transferred to pediatrics after birth), and neonatal intensive care unit (NICU) admission ((transferred to NICU after birth).

\section{Statistical analysis}

Data were analyzed using the SPSS 21.0 statistical software. The cohort characteristics were described using the chi-square test for categorical variables, while continuous variables were expressed as means \pm SD. $P<0.05$ was statistically significant. Logistic regression analysis was performed to adjust the confounders, including maternal age, BMI, value of AMH, infertile years, current cycle, AFC, cause of infertility, number of oocytes retrieved, endometrial thickness at the date of transplantation, number of high-quality embryos, and embryo stage.

\section{Results}

Baseline characteristics

Baseline characteristics of the cohorts in both fresh and frozen cycles are illustrated in Table 1.

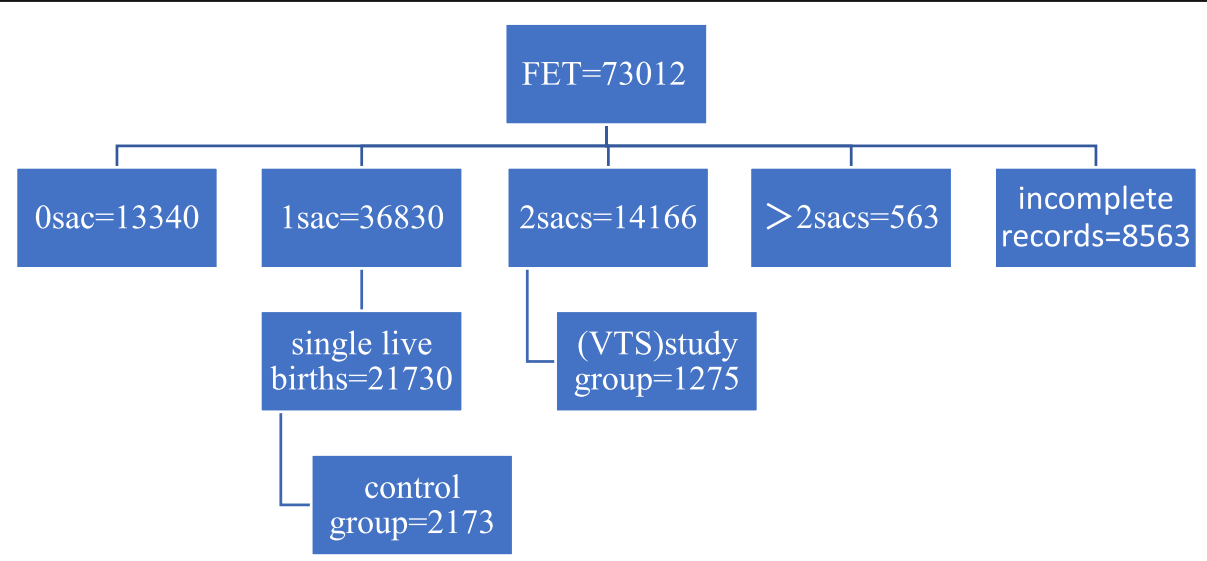

Fig. 2 Number of included and excluded cycles in FET cycles 
Table 1 Baseline characteristics of the two cohorts in fresh ET and FET cycles

\begin{tabular}{|c|c|c|c|c|c|c|c|c|}
\hline & Fresh cycles & & & & Frozen cycle & & & \\
\hline & $\begin{array}{l}\text { Study } \\
\text { group } \\
N=1196\end{array}$ & $\begin{array}{l}\text { Control } \\
\text { group } \\
N=1576\end{array}$ & $\begin{array}{l}P \\
\text { value }\end{array}$ & $\begin{array}{l}t / x^{2} \\
\text { value }\end{array}$ & $\begin{array}{l}\text { Study } \\
\text { group } \\
N=1275\end{array}$ & $\begin{array}{l}\text { Control } \\
\text { group } \\
N=2173\end{array}$ & $\begin{array}{l}P \\
\text { value }\end{array}$ & $\begin{array}{l}\mathrm{t} / \mathrm{x}^{2} \\
\text { value }\end{array}$ \\
\hline Age & $29.5 \pm 3.9$ & $29.8 \pm 4.2$ & $0.031^{*}$ & -2.16 & $30.7 \pm 4.9$ & $30.2 \pm 4.8$ & $0.001^{*}$ & 3.20 \\
\hline$<35$ & $1094(91.5)$ & 1406 (89.2) & 0.061 & 3.47 & $913(71.6)$ & $1586(73.0)$ & 0.698 & 0.70 \\
\hline$\geq 35$ & $102(8.5)$ & $117(10.8)$ & & & $362(28.4)$ & $587(27.0)$ & & \\
\hline BMI & $22.9 \pm 3.0$ & $23.0 \pm 3.1$ & 0.15 & -1.45 & $23.0 \pm 2.5$ & $22.8 \pm 2.3$ & $0.016^{*}$ & 2.42 \\
\hline Infertile year & $1.8 \pm 1.3$ & $1.8 \pm 1.8$ & 0.86 & 0.18 & $2.5 \pm 1.5$ & $2.7 \pm 1.5$ & $0.001^{*}$ & 3.23 \\
\hline Cause of infertility & & & 0.314 & 1.01 & & & 0.177 & 0.82 \\
\hline Tubal factor & $788(65.9)$ & $1067(67.7)$ & & & $826(64.8)$ & $1458(67.1)$ & & \\
\hline Male factor & $408(34.1)$ & $509(32.3)$ & & & 449 (35.2) & $715(32.9)$ & & \\
\hline Current cycle & $1.4 \pm 0.7$ & $1.4 \pm 1.1$ & 0.96 & 0.055 & $2.4 \pm 1.8$ & $2.4 \pm 1.6$ & 0.194 & 1.30 \\
\hline bFSH & $7.0 \pm 2.2$ & $7.0 \pm 3.7$ & 0.84 & -0.21 & $7.9 \pm 2.6$ & $7.7 \pm 1.8$ & 0.057 & 1.91 \\
\hline bE2 & $37.1 \pm 8.9$ & $36.5 \pm 9.1$ & 0.101 & 1.64 & $48.7 \pm 16.0$ & $49.5 \pm 12.4$ & 0.146 & -1.45 \\
\hline bLH & $4.6 \pm 3.3$ & $4.3 \pm 2.8$ & 0.21 & 1.82 & $4.4 \pm 2.5$ & $4.3 \pm 2.1$ & 0.201 & 1.28 \\
\hline PRL & $\begin{array}{l}414.7 \pm \\
178.8\end{array}$ & $402.0 \pm 204.8$ & 0.089 & 1.703 & $\begin{array}{l}4.9 .3 \pm \\
254.9\end{array}$ & $409.9 \pm 184.8$ & 0.939 & -0.077 \\
\hline $\mathrm{AMH}$ & $5.4 \pm 0.60$ & $5.3 \pm 0.67$ & $0.029^{*}$ & 0.089 & $5.1 \pm 2.6$ & $5.3 \pm 2.8$ & 0.068 & -1.824 \\
\hline AFC & $15.7 \pm 4.4$ & $15.5 \pm 5.4$ & 0.55 & 0.60 & / & / & / & / \\
\hline Number of oocytes retrieved & $10.5 \pm 4.5$ & $10.6 \pm 3.9$ & 0.53 & 0.62 & / & / & / & / \\
\hline Number of available embryos & $8.2 \pm 1.2$ & $8.0 \pm 1.6$ & $0.01^{*}$ & 2.57 & / & / & / & / \\
\hline Number of high-quality embryos & $5.1 \pm 2.6$ & $4.8 \pm 2.4$ & $0.003^{*}$ & 2.95 & / & / & / & / \\
\hline embryo stage & & & $0.000^{*}$ & 126.4 & & & $0.01^{*}$ & 6.57 \\
\hline cleavage-stage embryo & $1015(84.9)$ & $1040(66.0)$ & & & $874(68.5)$ & $1395(64.2)$ & & \\
\hline blastocyst & $181(15.1)$ & $536(34.0)$ & & & 401 (31.4) & 778 (35.8) & & \\
\hline $\begin{array}{l}\text { endometrial thickness at the day of } \\
\text { transplantation }\end{array}$ & $11.6 \pm 1.3$ & $11.7 \pm 1.1$ & $0.002^{*}$ & -3.1 & $10.3 \pm 1.9$ & $10.2 \pm 1.5$ & 0.091 & 1.69 \\
\hline mode of delivery & & & $0.000^{*}$ & 67.0 & & & $0.000^{*}$ & 210.9 \\
\hline cesarean section & $766(64.0)$ & $1233(78.2)$ & & & $851(66.7)$ & 1899 (87.4) & & \\
\hline vaginal delivery & $430(36.0)$ & $343(21.8)$ & & & $424(33.3)$ & $274(12.6)$ & & \\
\hline
\end{tabular}

${ }^{*} p<0.05$ was statistically significant

Firstly, for the fresh ET cycles, the maternal age in control group was higher than that in study group $(29.8 \pm 4.2$ VS $29.5 \pm 3.9, p=0.031)$. At the same time, the value of AMH was also higher in study group compared with that in control group (5.4 \pm 0.60 VS $5.3 \pm$ $0.67, p=0.029$ ). Moreover, more high quality embryos obtained from the fresh cycles and more cleavage-stage embryos were included in study group than those in control group, which were $(5.1 \pm 2.6$ VS $4.8 \pm 2.4$, $p=0.003)$ and $(84.9 \% \mathrm{~V} \mathrm{S66.0 \% ,} p=0.000)$, respectively. But the endometrial thickness at the date of transplantation in control group was greater than that in study group (11.7 \pm 1.1 VS $11.6 \pm 1.3, p=0.002)$. More women received cesarean section in control group than in study group (78.2 VS 64\%, $p=0.000$ ) (Table 1).

Secondly, for the FET cycles, the maternal age and BMI were higher in study group than in control group, which were (30.7 \pm 4.9 VS $30.2 \pm 4.8, p=0.001)$ and $(23.0 \pm 2.5$ VS $22.8 \pm 2.3, p=0.0016)$, respectively. In addition, the infertile year was lower in study group compared with that in control group $(2.5 \pm 1.5$ VS $2.7 \pm$ $1.5, p=0.001)$. Besides, there were more cleavage-stage embryos included in study group than those in control group (68.5\% VS $64.2 \%, p=0.01)$, and more infants are delivered through cesarean section in control group than in study group $(87.4 \%$ VS $66.7 \%, p=0.000)$ (Table 1$)$.

\section{Primary outcomes}

\section{Neonatal outcomes of singleton live births in the fresh ET cycles}

In the fresh ET cycles, the BW and gestational age in study group were lower than those in control group, which were $(2962.4 \pm 563.1$ vs. $3104.9 \pm 498.5, p=0.000)$ and $(262.8 \pm$ 8.4 vs. $268.9 \pm 13.9, p=0.000$ ), respectively. Relative to 


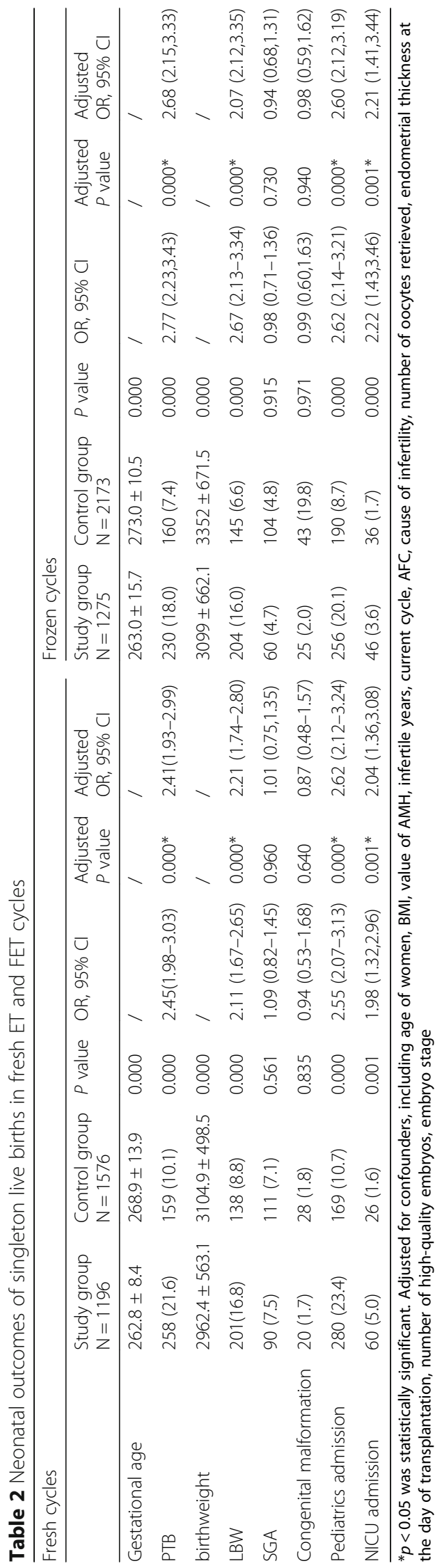


control group, the study group was linked with increased risks of PTB (adjusted odds ratio (aOR) 2.45, 95\% CI: 1.98-3.03, adjusted $p=0.000$ ), LBW (aOR2.11, 95\% CI: $1.67-2.65$, adjusted $p=0.000$ ), pediatric admission (aOR 2.55, 95\% CI2.07-3.13, adjusted $p=0.000$ ), and NICU admission (aOR 1.98,95\% CI1.32-2.96, adjusted $p=0.001$ ), but there were no statistically significant differences in the risks of SGA (aOR 1.09,95\% CI0.82-1.45, adjusted $p=0.960$ ) and congenital malformation (aOR 0.94, 95\% CI0.53-1.68, adjusted $p=0.640$ ) between the two groups (Table 2).

Neonatal outcomes of singleton live births in the FET cycles In the FET cycles, the gestational age and BW in study group were lower than those in control group, which were $(263.0 \pm 15.7$ vs. $273.0 \pm 10.5, \quad p=0.000)$ and $(3099 \pm 662.1$ vs. $3352 \pm 671.5)$, respectively. The study group was associated with increased risks of PTB (aOR2.45, 95\% CI: 2.23-3.43, adjusted $p=0.000$ ), LBW (aOR 2.67, 95\% CI: 2.13-3.34, adjusted $p=0.000$ ), pediatric admission (aOR2.62, 95\% CI2.14-3.21, adjusted $p=0.000$ ), and NICU admission (aOR 2.22, 95\% CI1.43, 3.46 , adjusted $p=0.001$ ) compared with those in control group, but differences in the risks of SGA (aOR 0.98, 95\% CI0.71-1.36, adjusted $p=0.730$ ) and congenital malformation (aOR 0.99, 95\% CI0.60, 1.63, adjusted $p=0.940$ ) were not statistically significant between the two groups (Table 2).

\section{Discussion}

It is discovered in this retrospective cohort study that, for both fresh and frozen cycles, the study groups have increased risks of LBW, PTB, pediatric admission and NICU admission relative to those in control groups. However, no increased risks of SGA or congenital malformation are observed in singleton live births in both the fresh and frozen ART cycles following DET.

This study has provided an important supplement to the existing literature, which confirms that VTS may result in higher risks of LBW, PTB, pediatric admission and NICU admission. Our findings are consistent with the conclusions obtained from previous studies, systematic reviews and meta-analyses. However, no study has recruited infertile couples with only tubal factors or male factor (lean and weak sperm disease). Such a study design is critical and necessary, which may avoid uncontrolled bias. For instance, polycystic ovary syndrome (PCOS) has been recognized as an endocrine disease related to the increased risk of adverse perinatal outcomes $[14,15]$. Sharma et al. found that the presence of adenomyosis might contribute to the adverse effects on the IVF outcomes in terms of the clinical pregnancy rate, live birth rate and miscarriage rate [16]. Additionally, Wang LF et al. suggested that pre-pregnancy obesity might result in the high prevalence of macrosomia, which increased the mean BW in cohort analysis [17]. Therefore, it is crucial to recruit the infertile patients with tubal factors and male factors alone, to investigate the differences between the two groups in our study. Also, this study has particularly compared the perinatal outcomes in singleton live births between the groups with initial single sac and initial double sacs following DET. Our results has indicated higher risks of LBW and PTB between patients with and without VTS following DET in both the fresh and frozen cycles. According to an earlier study, compared with single births obtained from SET, PTB and LBT infants are more likely to develop spontaneous reduction in the initial multiple pregnancies to singleton fetuses following transfer of multiple embryos [12]. Almoq. B et al. held that pregnancy with VTS was linked with adverse obstetric outcomes (PTB and LBW) relative to those in the initial singleton pregnancy of IVF [18]. Furthermore, SUN et al. believed that the VTS survivors displayed a higher incidence of LBW than that in singleton fetuses from single pregnancies in IVF-ET [19]. Besides, it is also suggested in previous results that, the early death of a pair of twins may improve the pregnancy outcomes. But there may be more adverse complications when continuing the twin pregnancy [20]. Analysis by Timur $\mathrm{H}$ et al. indicated that VTS patients were more likely to develop LBW, very low birthweight (VLBW), intrauterine growth restriction and pre-eclampsia [2123]. What's more, Zhu Y et al. revealed that VTS could affect the obstetric outcomes in survivors, but the impact of VTS was unstable. Yet it is too early to conclude that VTS will produce adverse obstetric outcomes, such a statement may also decrease their anxiety with VTS [24]. Our study shows that the rate of cesarean section is higher in the control group, because of the strong demand of women for cesarean section. Treatment of infertile couples with years of ART has brought about great panic, and these couples are more willing to choose cesarean section instead of facing the uncertainty of delivery, which is quiet common in China. Doctors will also agree with them. Fetal weight is also estimated before delivery, and there are many macrosomia and infants of normal BW, so most women are more willing to choose cesarean section to avoid the risk of huge children .

In this study, there are no statistically significant differences in SGA and congenital malformation between the two groups in both fresh and frozen ART cycles following DET, which may be affected by the strict inclusion criteria. Probably, such results may be caused by the fact that people choose to induce labor when SGA (especially in the case of abnormal chromosome) and congenital malformation are detected in middle pregnancy. Conversely, Luke suggested that the risk of 
moderate growth restriction in singletons was increased following transfer of multiple embryos relative to that after SET, thus demonstrating a significant adverse effect on the intrauterine growth following the multiple embryos transfer. However, it remains unclear about whether such effect can be ascribed to the compromised embryo quality, degenerated implantation sites, or other factors [25]. Typically, the higher incidence of VTS may account for the possible mechanism affecting the incidence of LBW in the study group. La Sala et al. suggested that VTS induced a deleterious effect on the ongoing pregnancy due to blood shunting from vascular anastomoses in the surviving twin placenta [26]. Besides, we found that after the dead embryo at middle or late pregnancy came out of the uterus, the surviving embryo were born in a short time, which might increase the risk of PTB, reduce the average BW, and elevate the possibilities of pediatrics admission as well as NICU admission. Nonetheless, such event is extremely rare (about 1 / 1000), which does not make an increase the risk of adverse outcomes. Most VTS occur in early pregnancy (7 weeks to 12 weeks), which is the real dominant factor of adverse outcomes. Additionally, chronic inflammation may account for the other speculation for the impact of VTS on the surviving twin [27]. Regrettably, no explanation is available for such speculation.

\section{Strengths and limitations}

The strengths of our research are as follows: all cycles are performed in the single center, which might reduce the internal bias (e.g., the laboratory technology, and operational procedures). Furthermore, we targets cycles with the tubal and male factors and rule out cycles with other infertility factors. However, previous relevant studies comparing neonatal outcomes between these groups did not exclude these cycles.

Some limitations exist in this study. One is the inherent characteristic of retrospective cohort study. Moreover, we do not collect information about the potential confounders, such as maternal smoking, drinking, previous history of abortion and different medical conditions during pregnancy. Additionally, further studies need to be designed to explore potential biological mechanism associated with adverse obstetric outcomes.

\section{Conclusions}

Our study finds that singleton live births with VTS have higher risks of LBW, PTB, pediatric admission and NICU admission than those without VTS in both the fresh and frozen cycles, even after adjusting for confounders. However, no increased risks of SGA or congenital malformation are observed in singleton live births in both the fresh and frozen ART cycles following DET.

\section{Abbreviations}

ART: Assisted Reproductive Technology; FET: Frozen embryo transfer; LBW: Low birthweight; PTB: Preterm birth; SET: Selective embryo transfer; VTS: Vanishing twin syndrome

\section{Acknowledgements}

Nil.

\section{Authors' contributions}

GYC and YJF designed the study and selected the populations to be included and excluded. XZY, MMK, SSM, GWJ and ZW were involved in data extraction and analysis. GYC and FHF reviewed the data. YJF was responsible for drafting this article. All authors had approved the final version of the manuscript.

\section{Funding}

We did not receive any funding for this study.

Availability of data and materials

All data were included in this article.

Ethics approval and consent to participate

This study was approved by the Ethical Committee of The Third Affiliated Hospital of Zhengzhou University.

\section{Consent for publication}

Not applicable.

\section{Competing interests}

The authors declare that they have no competing interests.

Received: 14 April 2019 Accepted: 4 July 2019

Published online: 20 July 2019

\section{References}

1. Zander-Fox DL, Tremellen K, Lane M. Single blastocyst embryo transfer maintains comparable pregnancy rates to double cleavage-stage embryo transfer but results in healthier pregnancy outcomes. Aust N Z J Obstet Gynaecol. 2011;51(5):406-10.

2. Pandey S, Shetty A, Hamilton M, Bhattacharya S, Maheshwari A. Obstetric and perinatal outcomes in singleton pregnancies resulting from IVF/ICSI: a systematic review and meta-analysis. Hum Reprod Update. 2012;18(5): 485-503.

3. Templeton A, Morris JK. Reducing the risk of multiple births by transfer of two embryos after in vitro fertilization. N Engl J Med. 1998;339(9):573-7.

4. Pinborg A. IVF/ICSI twin pregnancies: risks and prevention. Hum Reprod Update. 2005;11(6):575-93.

5. Bechoua S, Astruc K, Thouvenot S, Girod S, Chiron A, Jimenez C, et al. How to demonstrate that eSET does not compromise the likelihood of having a baby? Hum Reprod (Oxford, England). 2009;24(12):3073-81.

6. Cutting R, Morroll D, Roberts SA, Pickering S, Rutherford A. Elective single embryo transfer: guidelines for practice British Fertility Society and Association of Clinical Embryologists. Hum Fertil (Cambridge, England). 2008;11(3):131-46.

7. Gianaroli L, Racowsky C, Geraedts J, Cedars M, Makrigiannakis A, Lobo R. Best practices of ASRM and ESHRE: a journey through reproductive medicine. Hum Reprod (Oxford, England). 2012;27(12):3365-79.

8. De Sutter P, Delbaere I, Gerris J, Verstraelen H, Goetgeluk S, Van der Elst J, et al. Birthweight of singletons after assisted reproduction is higher after single- than after double-embryo transfer. Hum Reprod (Oxford, England). 2006;21(10):2633-7.

9. Joshi N, Kissin D, Anderson JE, Session D, Macaluso M, Jamieson DJ. Trends and correlates of good perinatal outcomes in assisted reproductive technology. Obstet Gynecol. 2012;120(4):843-51.

10. Innitsky S, Hughes L, Tekpetey F, Abu Rafea B, Vilos G, Vilos A. Elective Single Embryo Transfer in the Setting of Funded In Vitro Fertilization: Two Years' Experience in an Ontario Hospital-Based Fertility Clinic. J Obstet Gynaecol Can: JOGC. 2019:41(4):421-7.

11. Dickey RP, Taylor SN, Lu PY, Sartor BM, Storment JM, Rye PH, et al. Spontaneous reduction of multiple pregnancy: incidence and effect on outcome. Am J Obstet Gynecol. 2002;186(1):77-83. 
12. Kamath MS, Antonisamy B, Selliah HY, Sunkara SK. Perinatal outcomes of singleton live births with and without vanishing twin following transfer of multiple embryos: analysis of 113784 singleton live births. Hum Reprod (Oxford, England). 2018;33(11):2018-22.

13. Martin AS, Chang J, Zhang Y, Kawwass JF, Boulet SL, McKane P, et al. Perinatal outcomes among singletons after assisted reproductive technology with single-embryo or double-embryo transfer versus no assisted reproductive technology. Fertil Steril. 2017;107(4):954-60.

14. Yu HF, Chen HS, Rao DP, Gong J. Association between polycystic ovary syndrome and the risk of pregnancy complications: a PRISMA-compliant systematic review and meta-analysis. Medicine. 2016;95(51):e4863.

15. Li Y, Lin H, Pan P, Yang D, Zhang Q. Impact of central obesity on women with polycystic ovary syndrome undergoing in vitro fertilization. BioResearch Open Access. 2018;7(1):116-22.

16. Sharma S, Bathwal S, Agarwal N, Chattopadhyay R, Saha I, Chakravarty B. Does presence of adenomyosis affect reproductive outcome in IVF cycles? A retrospective analysis of 973 patients. Reprod BioMed Online. 2019;38(1):13-21

17. Wang LF, Wang HJ, Ao D, Liu Z, Wang Y, Yang HX. Influence of prepregnancy obesity on the development of macrosomia and large for gestational age in women with or without gestational diabetes mellitus in Chinese population. J Perinatol. 2015;35(12):985-90.

18. Almog B, Levin I, Wagman I, Kapustiansky R, Lessing JB, Amit A, et al. Adverse obstetric outcome for the vanishing twin syndrome. Reprod BioMed Online. 2010;20(2):256-60.

19. Shebl O, Ebner T, Sommergruber M, Sir A, Tews G. Birth weight is lower for survivors of the vanishing twin syndrome: a case-control study. Fertil Steril. 2008;90(2):310-4.

20. Romanski PA, Carusi DA, Farland LV, Missmer SA, Kaser DJ, Walsh BW, et al. Perinatal and Peripartum outcomes in vanishing twin pregnancies achieved by in vitro fertilization. Obstet Gynecol. 2018;131(6):1011-20.

21. Timur H, Aksoy RT, Tokmak A, Timur B, Coskun B, Uygur D, et al. Maternal and perinatal outcomes of dichorionic diamniotic twin pregnancies diagnosed with vanishing twin syndrome: a retrospective analysis from a single clinical center. Ginekol Pol. 2018;89(1):30-4.

22. Magnus MC, Ghaderi S, Morken NH, Magnus P, Bente Romundstad L, Skjaerven $\mathrm{R}$, et al. Vanishing twin syndrome among ART singletons and pregnancy outcomes. Hum Reprod (Oxford, England). 2017;32(11):2298-304.

23. Petrini AC, Pereira N, Lekovich JP, Elias RT, Spandorfer SD. Early spontaneous multiple fetal pregnancy reduction is associated with adverse perinatal outcomes in in vitro fertilization cycles. Womens Health (London, England). 2016;12(4):420-6.

24. Zhu Y, Chen Y, Feng Y, Yu D, Mo X. Association between maternal body mass index and congenital heart defects in infants: a meta-analysis. Congenit Heart Dis. 2018;13(2):271-81.

25. Luke B, Brown MB, Stern JE, Grainger DA, Klein N, Cedars M. Effect of embryo transfer number on singleton and twin implantation pregnancy outcomes after assisted reproductive technology. J Reprod Med. 2010;55(9-10):387-94.

26. La Sala GB, Villani MT, Nicoli A, Gallinelli A, Nucera G, Blickstein I. Effect of the mode of assisted reproductive technology conception on obstetric outcomes for survivors of the vanishing twin syndrome. Fertil Steril. 2006;86(1):247-9.

27. Luke B, Brown MB, Grainger DA, Stern JE, Klein N, Cedars MI. The effect of early fetal losses on singleton assisted-conception pregnancy outcomes. Fertil Steril. 2009;91(6):2578-85.

\section{Publisher's Note}

Springer Nature remains neutral with regard to jurisdictional claims in published maps and institutional affiliations.

Ready to submit your research? Choose BMC and benefit from:

- fast, convenient online submission

- thorough peer review by experienced researchers in your field

- rapid publication on acceptance

- support for research data, including large and complex data types

- gold Open Access which fosters wider collaboration and increased citations

- maximum visibility for your research: over $100 \mathrm{M}$ website views per year

At BMC, research is always in progress.

Learn more biomedcentral.com/submissions 